\title{
The Research of Site Supervision of Aids Screening Laboratory in Sichuan Province During 2011-2020: A Laboratory Capacity- based Continuity Study
}

\section{Ling Li}

Sichuan Center for Disease Control and Prevention

Li Ye

Sichuan Center for Disease Control and Prevention

Hong Lu Liu

Sichuan Center for Disease Control and Prevention

\section{Geng Sheng Zhou}

Sichuan Center for Disease Control and Prevention

Jia Yu

Sichuan Center for Disease Control and Prevention

\section{Dong Bing Wei}

Sichuan Center for Disease Control and Prevention

\section{Ling Su}

Sichuan Center for Disease Control and Prevention

\section{Hong Yang}

Sichuan Center for Disease Control and Prevention

\section{Yi Ping Li}

Sichuan Center for Disease Control and Prevention

\section{Chang Zhou}

Sichuan Center for Disease Control and Prevention

\section{Yan Zhang}

Sichuan Center for Disease Control and Prevention

\section{Shu Liang}

Sichuan Center for Disease Control and Prevention

Dan Yuan ( $\nabla$ ydtv1130@163.com )

Sichuan Center for Disease Control and Prevention

\section{Research Article}

Keywords: HIV/AIDS, screening laboratory, quality control, site supervision

Posted Date: August 23rd, 2021

DOI: https://doi.org/10.21203/rs.3.rs-807707/v1

License: (9) (i) This work is licensed under a Creative Commons Attribution 4.0 International License. Read Full License 


\section{Abstract}

Background: Expanding the scale of Human immunodeficiency virus (HIV) testing is long-term strategy for acquired immune deficiency syndrome (AIDS) prevention and control. This study analyzes the capacity of HIV screening laboratory operation to find influencing factors and guarantee quality of test. The result could also provide reference value for management of AIDS laboratories in other provinces and even abroad.

Methods: Randomly checking AIDS screening laboratories in 21 cities and counties (districts) every year and also filling out evaluation form of site supervision. Analyzing the influence factors of HIV screening laboratory operation though Logistic regression.

Result: From 2011 to 2020, there were 68, 75, 81, 82, 87, 80, 33, 57, 85 and 87 HIV screening laboratories conducted site supervision respectively, of which 60(88.24\%), 74 (98.67\%), 76 (93.83\%), 81(98.78\%), 60(68.97\%), 51(63.75\%), 23(69.70\%), $41(71.93 \%), 59(69.41 \%)$ and $60(68.97 \%)$ had excellent results. It was found that the excellence rate of each institution was relatively stable during 2011-2014, while the overall score of each regional laboratory in 2015 fluctuated significantly than 2015 before and all of excellence rate has declined. Hospitals and centers for disease control and prevention (CDC) were with higher frequency of assessment. Multivariate logistic regression analysis found these following variables were significant influencing factors of laboratory quality, including staffing, standard operating procedure (SOP) and management system, periodic calibration of equipment, standardization of HIV testing, uniqueness of sample number, standardized use of quality control materials, standard drawing of quality control chart, biosafety facilities .

Conclusion: The overall operation of HIV screening laboratories in the whole province is good and the quality management can normatively meet the requirements, which also meet the demand of expanding HIV testing. It also has lots of questions influencing laboratory quality, so each part is still strictly required to ensure laboratory work well.

\section{Background}

Since the first AIDS case was reported in Sichuan Province in 1992, the number of HIV infected persons and cases in Sichuan Province is increasing annually, Sichuan Province has become one of the main epidemic areas in China ${ }^{[1]}$. The incidence and mortality of HIV have increased from 10.12 per 100,000 and 2.00 per $100 \otimes 000$ in 2011 to 31.76 per $100 \otimes 000$ and 5.92 per $100 \otimes 000$ in 2019 , respectively ${ }^{[2-4]}$. The improvement of HIV detection technology and diagnostic reagent quality at home and abroad has promoted the progress of HIV prevention and cure over recent years. China's 13th Five Year Action Plan for HIV/AIDS Containment and Prevention requires accomplishing three goals, which including more than $90 \%$ of infected people and patients who has been diagnosed and aware of their own psysical condition. HIV testing is the first step in AIDS prevention and expanding the scale of testing is also a long-term strategy for AIDS prevention and control. However, the expansion of testing work is closely related to the continuous improvement of the laboratory network, the number of HIV testing sites, screening and certification laboratories in Sichuan Province has increased from 1194, 552 and 27 in 2011 to 4885, 753 and 74 in 2020, respectively, which covering the whole province included 183 districts and counties. As of 31 December 2020, Sichuan Province has 5712 AIDS test institutions and the number of testing reached 37.7 million, an increase of 855.38 \% from 2011(Fig. 1). The testing quality of HIV screening laboratories has a great impact on the case detection of HIV. With the increasing of testing institutions and expanded testing, the guarantee of testing quality is extremely important. In order to strengthen the management of HIV testing laboratories, improve the testing level, and instantly find and solve the problems, Sichuan Provincial Center for Disease Control and Prevention has started the site supervision of HIV testing laboratories in the whole province since 2009 and Sichuan Province is also the first province in China to start the site supervision of AIDS testing laboratories. This paper analyzes the result of site supervision of AIDS screening laboratories during 2011-2020, which may provide reference value for the management of AIDS laboratories in other provinces and even abroad.

\section{Methods}


1.10bjective From 2011 to 2020, randomly checking AIDS screening laboratories in 21 cities and counties (districts) every year, which included local CDC, medical institutions, maternal and child care centre and other institutions.

1.2 Assessment method Organized by the HIV / AIDS confirmation center laboratory of Sichuan Center for Disease Control and Prevention. The panel members of HIV / AIDS confirmation laboratories in 21 cities were selected as members of the site supervision expert group, who will check and score on HIV / AIDS screening laboratories. The members of the expert group did not participate in the site supervision of the screening laboratories in their own workplace.

1.3The assessment indexes Taking the assessment indexes as the analysis variables, including the qualification of experimenter, the normalization of materials'filing, SOP, management system, quality management of surveillance area, standardization of laboratory network information filling, equipment management, standardization of HIV screening report and retest test sheet, uniqueness of HIV sample number, the quality control,laboratory area and personal protective equipment, biosafety facilities, reagent use and management. Specific scoring plan may refer to "Supervision Program of AIDS Testing Laboratory in Sichuan Province" issued by Sichuan Center for Disease Control and Prevention.

1.4 Score standard Total score $\geq 90$ was defined as excellent and total score $<90$ was defined as non-excellent.

1.5 Statistical analysis Using EXCEL to establish a database and carry out description and statistical analysis by SPSS 25.0 software, the variables were analyzed by single factor logistic regression analysis, which $\mathrm{P}<0.2$ for multivariate regression analysis and $\mathrm{P}<0.05$ was considered as statistically significant.

\section{Results}

1.1The general information of site supervision during 2011-2020

From 2011 to 2020 , there were $68,75,81,82,87,80,33,57,85$ and 87 HIV screening laboratories conducted site supervision respectively, of which 60(88.24\%), 74(98.67\%), 76(93.83\%), 81(98.78\%), 60(68.97\%), 51(63.75\%), 23(69.70\%), 41(71.93\%), $59(69.41 \%)$ and $60(68.97 \%)$ had excellent results. During 2011-2020, the laboratory participated site supervision covered the whole province included 173 districts and counties. Among them, 25 regions had more than 7 times of site supervision, such as Xichang, Meishan, Xuzhou, Lizhou, Jingyang. There were 11 areas had not been assessed, such as the area of Jinniu, the Qingbaijiang, Wenjiang, Xinjin, Dayi. (Fig. 2)

B. The distribution Map of frequency of site supervision, 2011-2020

C. The distribution Map of HIV screening laboratory in 2011

D. The distribution Map of HIV screening laboratory in 2020

\section{Note}

The map in this figure is designed by using the ArcMap 10.6 software.

During 2011-2020, perform site supervision institution covered hospitals, CDC, maternal and child care center, blood donation and supply institutions and the judiciary. The proportion of site supervision in hospital and CDC had increased gradually, and institution with higher frequency of supervision was in hospitals and CDC. The specific distribution is shown in Fig. 3.

\section{Note}

2017 and 2018 were two years to complete a round of site supervision, so the numbers differed significantly from other years

1.2 AID/HIV screening laboratory scores of each region in Sichuan province during 2011-2020

The average scores of 21 cities in the past 10 years were analyzed and it can be seen that there was no significant difference in the laboratory conditions of cities before 2015. But the overall scores of laboratories in all regions in 2015 were fluctuated than 2015 before. And the scores of Chengdu, Zigong, Panzhihua, Nanchong, Aba and Ganzi have obvious fluctuations (Table 1). 
Table 1

The average score of cities in Sichuan

\begin{tabular}{|c|c|c|c|c|c|c|c|c|c|c|}
\hline & 2011 & 2012 & 2013 & 2014 & 2015 & 2016 & 2017 & 2018 & 2019 & 2020 \\
\hline Chengdu & 96.28 & 97.89 & 95.38 & 97 & 88.96 & 87.17 & / & 90.8 & 93 & 85.7 \\
\hline Zigong & 96.7 & 95.33 & 93.33 & 83.33 & 95.33 & 92.5 & / & 92.13 & 90.5 & 86.67 \\
\hline Panzhihua & 94.62 & 97.33 & 96 & 99 & 92 & 96 & / & 95.83 & 94.5 & 89.67 \\
\hline Luzhou & 98.63 & 96.75 & 87 & 93.63 & 88 & 83 & / & 86.25 & 94.25 & 95 \\
\hline Deyang & 97.3 & 94.33 & 98 & 98.33 & 92.83 & 90.9 & I & 96.5 & 90.13 & 95.17 \\
\hline Mianyang & 95.68 & 98 & 98.08 & 98.17 & 97.92 & 97.8 & / & 96 & 95.6 & 98.83 \\
\hline Guangyuan & 95.83 & 96.5 & 95.25 & 97.25 & 93.5 & 87.17 & / & 92.75 & 89 & 95.63 \\
\hline Suining & 98.33 & 97.25 & 96 & 98 & 90.88 & 79.5 & I & 97.33 & 97.13 & 93.38 \\
\hline Neijiang & 97.63 & 97.17 & 98.25 & 97.25 & 91.1 & 86.42 & / & 92 & 91.67 & 94.5 \\
\hline Leshan & 92.73 & 95.25 & 91 & 96.83 & 96.6 & 90.2 & / & 93.2 & 93.5 & 92.5 \\
\hline Nanchong & 98.9 & 96.67 & 97 & 97.67 & 79.25 & 87.33 & / & 93.88 & 92.33 & 85.75 \\
\hline Meishan & 92.77 & 93.67 & 95.67 & 96.5 & 90.75 & 91.33 & / & 78.88 & 93.5 & 95.17 \\
\hline Yibin & 93.73 & 96.67 & 94.8 & 97 & 86.71 & 86.5 & 92.67 & / & 92 & 91.25 \\
\hline Guangan & 96.7 & 98 & 96.5 & 94 & 95.25 & 80.67 & 93.32 & / & 93.63 & 94.5 \\
\hline Dazhou & 96.67 & 97.33 & 95.67 & 96.75 & 94.75 & 96.25 & 90.75 & / & 93.5 & 93.33 \\
\hline Yaan & 90.8 & 96.38 & 84.83 & 96.67 & 84 & 89.17 & / & 93 & 90.67 & 93 \\
\hline Bazhong & 90 & 97 & 93.75 & 97.25 & 96.25 & 91.33 & / & 92.13 & 93.38 & 91.5 \\
\hline Ziyang & 94.87 & 98.13 & 97.67 & 96.67 & 93 & 86.33 & I & 92.38 & 92.5 & 93.67 \\
\hline Aba & 95.37 & 91 & 96 & 98 & 81.75 & 75.5 & 92.97 & / & 88.5 & 85.5 \\
\hline Ganzi & 81.25 & 97.33 & 94 & 96.75 & 89 & 89.75 & 86.17 & / & 92.33 & 83.33 \\
\hline Liangshan & 93.33 & 97 & 96 & 97.25 & 83.5 & 78.1 & 85.5 & 83.63 & 83.33 & 88.68 \\
\hline
\end{tabular}

1.3 The analysis of excellence rate of different institutions during 2011-2020

Through the analysis of the excellence rate of different types of assessment laboratories from 2011 to 2020, it was found that the excellence rate of each institution was relatively stable during 2011-2014, while the overall score of each regional laboratory in 2015 fluctuated significantly than 2015 before and all of excellent rate has declined (Table 2). 
Table 2

The excellence rate of site supervised laboratories in different institution types, 2011-2020

\begin{tabular}{|llllllllllll|}
\hline & $\mathbf{2 0 1 1}$ & $\mathbf{2 0 1 2}$ & $\mathbf{2 0 1 3}$ & $\mathbf{2 0 1 4}$ & $\mathbf{2 0 1 5}$ & $\mathbf{2 0 1 6}$ & $\mathbf{2 0 1 7}$ & $\mathbf{2 0 1 8}$ & $\mathbf{2 0 1 9}$ & $\mathbf{2 0 2 0}$ & Average \\
\hline Hospital & 83.87 & 100.00 & 90.48 & 97.56 & 64.58 & 52.50 & 55.56 & 70.83 & 64.00 & 53.06 & 73.24 \\
\hline $\begin{array}{l}\text { Maternal } \\
\text { and } \\
\text { child } \\
\text { care } \\
\text { centre }\end{array}$ & 100.00 & 100.00 & 100.00 & 100.00 & 44.44 & 54.55 & 100.00 & 50.00 & 80.00 & 85.71 & 81.47 \\
\hline CDC & 90.63 & 96.43 & 96.97 & 100.00 & 82.14 & 75.00 & 57.14 & 92.86 & 69.57 & 79.31 & 84.00 \\
\hline Others & 100.00 & 100.00 & 100.00 & 100.00 & 100.00 & 100.00 & $/$ & 100.00 & 100.00 & 0.00 & 88.89 \\
\hline ALL & 88.24 & 98.67 & 93.83 & 98.78 & 68.97 & 61.25 & 60.00 & 73.47 & 68.24 & 63.22 & 77.47 \\
\hline
\end{tabular}

1.4 The analysis of factors affecting excellence rate in screening laboratory

Of all studied variables, multivariate logistic regression analysis found that the following variables were significant influencing factors of laboratory quality, including staffing $(O R=3.12,95 \% \mathrm{Cl}=1.31-7.45)$, laboratory SOP and management $(O R=0.39$, $95 \% \mathrm{Cl}=0.18-0.86)$, periodic calibration of equipment $(\mathrm{OR}=0.35,95 \% \mathrm{Cl}=0.14-0.86)$, standardization of $\mathrm{HIV}$ testing $(\mathrm{OR}=$ $0.07,95 \% \mathrm{Cl}=0.02-0.21)$, uniqueness of sample number $(\mathrm{OR}=0.31,95 \% \mathrm{Cl}=0.11-0.89)$, standardized use of quality control materials $(\mathrm{OR}=0.15,95 \% \mathrm{Cl}=0.06-0.36)$, standard drawing of quality control chart $(\mathrm{OR}=0.21,95 \% \mathrm{Cl}=0.09-0.49)$, biosafety facilities $(\mathrm{OR}=0.44,95 \% \mathrm{Cl}=0.21-0.94)($ Table 3$)$. 
The influence factors of operation quality of 461 HIV screening laboratory in Sichuan

\begin{tabular}{|c|c|c|c|c|c|}
\hline Item & $\begin{array}{l}\text { The number of } \\
\text { excellent }\end{array}$ & $\begin{array}{l}\text { The rate of } \\
\text { excellent(\%) }\end{array}$ & Total & OR & AOR \\
\hline \multicolumn{6}{|l|}{ Building time } \\
\hline $\begin{array}{l}2010 \text { year and } \\
\text { before }\end{array}$ & 380 & 81.54 & 466 & 1 & 1 \\
\hline 2011 yearand after & 206 & 76.58 & 269 & $0.74(0.51 \sim 1.07)^{\star}$ & $0.74(0.35 \sim 1.56)$ \\
\hline \multicolumn{6}{|l|}{ Staffing } \\
\hline At least 5 people & 375 & 77.16 & 486 & 1 & 1 \\
\hline 6 or more people & 211 & 84.74 & 249 & $\begin{array}{l}1.64(1.10 \sim \\
2.46)^{\star \star}\end{array}$ & $\begin{array}{l}3.12(1.31 \sim \\
7.45)^{\star \star}\end{array}$ \\
\hline \multicolumn{6}{|c|}{ HIV laboratory personnel are qualified } \\
\hline Conformity & 584 & 79.67 & 733 & 1 & \\
\hline non-conformity & 2 & 1 & 2 & 1 & \\
\hline \multicolumn{6}{|c|}{ The actual operators are qualified } \\
\hline Conformity & 582 & 80.39 & 724 & 1 & 1 \\
\hline non-conformity & 4 & 36.36 & 11 & $\begin{array}{l}0.14(0.04 \sim \\
0.48)^{\star \star}\end{array}$ & $0.31(0.03 \sim 3030)$ \\
\hline \multicolumn{6}{|l|}{ Data archive } \\
\hline Conformity & 523 & 81.21 & 644 & 1 & 1 \\
\hline non-conformity & 63 & 69.23 & 91 & $\begin{array}{l}0.52(0.32 \sim \\
0.85)^{\star \star}\end{array}$ & $0.46(0.17 \sim 1.26)^{*}$ \\
\hline \multicolumn{6}{|c|}{ Laboratory SOP and management } \\
\hline Conformity & 359 & 81.04 & 443 & 1 & 1 \\
\hline non-conformity & 167 & 74.55 & 224 & $0.69(0.47 \sim 1.01)^{\star}$ & $\begin{array}{l}0.39(0.18 \sim \\
0.86)^{\star \star}\end{array}$ \\
\hline without judgement & 60 & 88.24 & 68 & & \\
\hline \multicolumn{6}{|c|}{ Quality control and on-site evaluation of HIV testing sites in the jurisdiction } \\
\hline Conformity & 290 & 68.08 & 426 & 1 & \\
\hline non-conformity & 5 & 83.33 & 6 & $2.29(0.27 \sim 19.82)$ & \\
\hline without judgement & 291 & 95.1 & 306 & & \\
\hline \multicolumn{6}{|c|}{ Standardization of laboratory network information filling } \\
\hline Conformity & 401 & 86.24 & 465 & 1 & 1 \\
\hline non-conformity & 10 & 66.67 & 15 & $\begin{array}{l}0.32(0.11 \sim \\
0.96)^{\star \star}\end{array}$ & $0.42(0.09 \sim 2.08)$ \\
\hline without judgement & 175 & 68.63 & 255 & & \\
\hline
\end{tabular}

Note: ${ }^{*} \mathrm{P}$ value $<0.2,{ }^{*} \mathrm{P}$ value $<0.05,{ }^{\star} \star \star \mathrm{P}$ value $<0.001$ 


\begin{tabular}{|c|c|c|c|c|c|}
\hline Item & $\begin{array}{l}\text { The number of } \\
\text { excellent }\end{array}$ & $\begin{array}{l}\text { The rate of } \\
\text { excellent(\%) }\end{array}$ & Total & OR & AOR \\
\hline Conformity & 58 & 69.05 & 84 & 1 & \\
\hline non-conformity & 2 & 66.67 & 3 & $0.90(0.08 \sim 10.33)$ & \\
\hline without judgement & 526 & 81.17 & 648 & & \\
\hline \multicolumn{6}{|c|}{ Normal operation of equipment and relevant records } \\
\hline Conformity & 483 & 80.5 & 600 & 1 & \\
\hline non-conformity & 103 & 76.3 & 135 & $0.78(0.50 \sim 1.22)$ & \\
\hline \multicolumn{6}{|c|}{ Thermostatic facilities } \\
\hline Conformity & 497 & 79.14 & 628 & 1 & \\
\hline non-conformity & 29 & 74.36 & 39 & $0.76(0.36 \sim 1.61)$ & \\
\hline without judgement & 60 & 88.24 & 68 & & \\
\hline \multicolumn{6}{|c|}{ Periodic calibration of equipment } \\
\hline Conformity & 519 & 82.12 & 632 & 1 & 1 \\
\hline non-conformity & 67 & 65.05 & 103 & $\begin{array}{l}0.40(0.26 \sim \\
0.63)^{\star \star \star}\end{array}$ & $\begin{array}{l}0.35(0.14 \sim \\
0.86)^{\star \star}\end{array}$ \\
\hline \multicolumn{6}{|c|}{ Standardization of HIV testing } \\
\hline Conformity & 254 & 95.49 & 266 & 1 & 1 \\
\hline non-conformity & 332 & 70.79 & 469 & $\begin{array}{l}0.11(0.06 \sim \\
0.21)^{\star \star \star}\end{array}$ & $\begin{array}{l}0.07(0.02 \sim \\
0.21)^{\star \star \star}\end{array}$ \\
\hline \multicolumn{6}{|c|}{ Standardization of HIV screening report } \\
\hline Conformity & 536 & 79.41 & 675 & 1 & \\
\hline non-conformity & 50 & 83.33 & 60 & $1.35(0.69 \sim 2.65)$ & \\
\hline \multicolumn{6}{|c|}{ Standardization of HIV retest test sheet } \\
\hline Conformity & 529 & 79.31 & 667 & 1 & \\
\hline non-conformity & 57 & 83.82 & 68 & $1.34(0.69 \sim 2.63)$ & \\
\hline \multicolumn{6}{|c|}{ Uniqueness of HIV sample number } \\
\hline Conformity & 471 & 80.1 & 588 & 1 & 1 \\
\hline non-conformity & 55 & 69.62 & 79 & $\begin{array}{l}0.57(0.33 \sim \\
0.96)^{\star \star}\end{array}$ & $\begin{array}{l}0.31(0.11 \sim \\
0.89)^{\star \star}\end{array}$ \\
\hline without judgement & 60 & 88.24 & 68 & & \\
\hline \multicolumn{6}{|l|}{ Outer quality control } \\
\hline Conformity & 352 & 72.58 & 485 & 1 & \\
\hline non-conformity & 19 & 76 & 25 & $1.20(0.47 \sim 3.06)$ & \\
\hline without judgement & 215 & 95.56 & 225 & & \\
\hline \multicolumn{6}{|c|}{ Standardized use of quality control materials } \\
\hline
\end{tabular}




\begin{tabular}{|c|c|c|c|c|c|}
\hline Item & $\begin{array}{l}\text { The number of } \\
\text { excellent }\end{array}$ & $\begin{array}{l}\text { The rate of } \\
\text { excellent(\%) }\end{array}$ & Total & OR & AOR \\
\hline Conformity & 436 & 81.19 & 537 & 1 & 1 \\
\hline non-conformity & 74 & 63.25 & 117 & $\begin{array}{l}0.39(0.26 \sim \\
0.62)^{\star \star \star}\end{array}$ & $\begin{array}{l}0.15(0.06 \sim \\
0.36)^{\star \star \star}\end{array}$ \\
\hline without judgement & 76 & 93.83 & 81 & & \\
\hline \multicolumn{6}{|c|}{ Standard drawing of quality control chart } \\
\hline Conformity & 482 & 83.1 & 580 & 1 & 1 \\
\hline non-conformity & 104 & 67.1 & 155 & $\begin{array}{l}0.42(0.28 \sim \\
0.62)^{\star \star \star}\end{array}$ & $\begin{array}{l}0.21(0.09 \sim \\
0.49)^{\star \star \star}\end{array}$ \\
\hline \multicolumn{6}{|c|}{ Correct analysis of quality control } \\
\hline Conformity & 512 & 79.63 & 643 & 1 & \\
\hline non-conformity & 74 & 80.43 & 92 & $1.05(0.61 \sim 1.82)$ & \\
\hline \multicolumn{6}{|c|}{ Quality control of rapid dignosis } \\
\hline Conformity & 332 & 74.11 & 448 & 1 & \\
\hline non-conformity & 44 & 69.84 & 63 & $0.81(0.45 \sim 1.44)$ & \\
\hline without judgement & 210 & 93.75 & 224 & & \\
\hline \multicolumn{6}{|c|}{ Laboratory area and personal protective equipment } \\
\hline Conformity & 432 & 79.85 & 541 & 1 & 1 \\
\hline non-conformity & 94 & 74.6 & 126 & $0.74(0.47 \sim 1.17)^{\star}$ & $0.83(0.28 \sim 2.41)$ \\
\hline without judgement & 60 & 88.24 & 68 & & \\
\hline \multicolumn{6}{|l|}{ Biosafety facilities } \\
\hline Conformity & 415 & 81.21 & 511 & 1 & 1 \\
\hline non-conformity & 171 & 76.34 & 224 & $0.75(0.51 \sim 1.09)^{\star}$ & $\begin{array}{l}0.44(0.21 \sim \\
0.94)^{\star \star}\end{array}$ \\
\hline \multicolumn{6}{|l|}{ Batch inspection } \\
\hline Conformity & 447 & 76.41 & 585 & 1 & \\
\hline non-conformity & 5 & 71.43 & 7 & $0.77(0.15 \sim 4.02)$ & \\
\hline without judgement & 134 & 93.71 & 143 & & \\
\hline \multicolumn{6}{|c|}{ Batch inspection with reagents used } \\
\hline Conformity & 444 & 76.55 & 580 & 1 & \\
\hline non-conformity & 8 & 66.67 & 12 & $0.61(0.18 \sim 2.07)$ & \\
\hline without judgement & 134 & 93.71 & 143 & & \\
\hline \multicolumn{6}{|c|}{ Storage and use records of reagents } \\
\hline Conformity & 540 & 80.12 & 674 & 1 & \\
\hline non-conformity & 46 & 75.41 & 61 & $0.76(0.41 \sim 1.40)$ & \\
\hline
\end{tabular}


Item which without judgement: these were not required to site supervision in 2011 included uniqueness of HIV sample number, thermostatic facilities, laboratory area and personal protective equipment. Standardized use of quality control materials, batch inspection and batch inspection with reagents used were not required to site supervision during 2011-2012. Item both outer quality control and quality control of rapid diagnosis were not asked to site supervision in 2011-2013. Laboratory SOP and management and quality control and on-site evaluation of HIV testing sites in the jurisdiction were not required to site supervision before 2015. Item both Standardization of laboratory network information filling and review the correctness of HIV laboratory test data in the jurisdiction were not judged because Laboratory network information system was shut down during 2016-2019.

\section{Discussion}

Sichuan Provincial Center for Disease Control and Prevention organized and carried out site supervision of HIV screening laboratories in the past 10 years, which found the overall operation of HIV screening laboratories in the whole province is good and the quality management can normatively meet the requirements of Management Measures for National AIDS Testing and National AIDS Testing Standards ( 2009 and 2015 versions ) ${ }^{[7-9]}$. During 2011-2020, laboratory supervised covers 173 districts and counties included hospitals, CDC, blood donation and supply institutions, the judiciary and other institutions each year. The excellent rate before 2015 is more than $85 \%$. With the revision and update of National AIDS testing technical specification, the requirements for laboratory testing and management are more rigorous and the deficiency of laboratories are also found. Which also resulted in the overall excellent rate of laboratories in 2015 was decreased, such as Chengdu, Zigong, Panzhihua, Nanchong, Aba, Ganzi. After continuous rectification in recent years, the excellent rate has also begun to improve every year.

This analysis found that the actual operators are qualified was an important factor affecting the quality of HIV screening laboratories. A total of 469 times of site supervision laboratory had sample testing problems included HIV screening and testing original records are not standardized, such as over altered, the original records and double test records are inconsistent, the experiment did not correspond with the reagent instructions and standard process, and did not add negative and positive control according to the kit instructions. It is suggested that each laboratory should strictly follow the reagent instructions, standardize the record filling, and reduce the frequency of modification. Similarly, some laboratories also have some problem, included did not have the uniform rules of sample number and not established database, no timely backup and place document on file, did not establish security measure. The above problems are also crucial to affect the experiment results. Therefore, laboratories should formulate unified numbering rules from sampling to detection, update the database in time and take confidentiality measures. In addition, both outer quality control and standard drawing of quality control chart are the vital factors affecting the normal operation of laboratories. The main problems included the quality control chart was not normative, not analyzed and corrected timely when it out of control. some laboratories did not do external quality control during rapid testing or only do positive quality control ${ }^{[10]}$. Laboratories could set up position which is specially responsible for the quality control chart. Meanwhile, Laboratories also should formulate the quality control rules are fit for own laboratory, clarify the solutions when quality control chart changed and out-of-control, strengthen the learning of quality control and regularly conduct quality control analysis seminars and assessment ${ }^{[11]}$. There are still some problems in the integrity and management of SOP documents, such as incomplete and untimely update of SOP and some laboratories even existed direct errors in SOP. Each laboratory should establish and update the SOP rules suitable for the laboratory to standardize the operation and management of the laboratory, make it easy to the experimenter follow the rules. Moreover, we could strengthen assessment effort of the sample and implement the disqualification mechanism of laboratories in the future work ${ }^{\text {[12] }}$

Secondly, AIDS laboratory staffing is one of the important factors to ensure the quality of testing, and the rate of institutional excellence with sufficient staffing is 3.12 times than poor staffing. Thus, AIDS laboratory should be equipped with personnel to ensure the normal and orderly operation of the experiment. We also found that the biosafety awareness of laboratory personnel was still inadequate, such as no eye washing device, non-standard of biological waste treatment and incomplete records. Some laboratory disinfectants did not match the requirements of Technical specification for disinfection of medical institutions (2012 version) ${ }^{[13]}$ and even not used biological waste bags, others used sharps and glassware. Besides the need 
of increasing the laboratory staffing, regular and learning should be carried out. Furthermore, it could set further study spot by the local municipal CDC to evaluate regular work of experimenters ${ }^{[14]}$. While improving the testing technology level of AIDS screening laboratories, we should also strengthen the biosafety awareness and reduce the occurrence of occupational exposure accidents ${ }^{[15]}$. When an accident occurs, it shall be strictly enforced in accordance with the requirements of Pocedures for occupational exposure to HIV infection ${ }^{[16]}$.

Finally, the normal operation of the equipment is of great significance to prerequisite for the quality assurance of experiment. The calibration of equipment was not in time may affect the accuracy of sample testing, such as the sampling error of pipettors, the systematic error caused by the inaccurate reading of the ELISA, the inaccurate measurement of the thermometer could result in reduction of quality of sample and reagent, inaccurate pressure of autoclave pressure gauge leads to incomplete sterilization and even biosafety hidden danger. It is suggested that worked out the plan of maintenance and calibration of each equipment and completed the archive files. The calibration of equipment should carry out and record on time ${ }^{[17]}$.

At present, AIDS publicity and education is not limited to its prevention, diagnosis and therapy, but also includes HIV testing. Now, colleges and universities have build HIV testing methods and testing processes into the curriculum and the government has incorporated the construction of laboratories into the annual check, so particular emphasis is placed on the laboratory testing. Through the site-assessment of HIV screening laboratories in Sichuan Province from 2011 to 2020, it can be seen that many factors such as staffing, quality of instruments and equipment, testing process, quality control and biosafety determine the normal operation of the laboratory. In recent year, the detection ability of most laboratories is gradually improved and management mode is steadily standardized, but each part is still strictly required to ensure operation of the laboratory work well. This survey also proved the necessity of site supervision, which can timely find, solve and reduce the possible risks in the operation of the laboratory and guarantee the accuracy of the test results. Each laboratory should strengthen technical training and guidance step by step. This paper also provides new ideas for the management mode of HIV laboratories in other provinces and even abroad.

This paper also has limitation. Firstly, this site supervision does not cover $100 \%$ of the districts and counties and the problem may be found insufficiently. Secondly, because of the revision of National AIDS testing technical specification and the adjustment of strategies for AIDS prevention and control, some indicators in the site supervision are accordingly changed, which may affect the comparability of results per year. Finally, the differences of both personal competence and understanding of various norms made this result is a certain subjectivity.

\section{Conclusions}

This study describes and analyzes operation quality of HIV screening laboratory in Sichuan, which finds influencing factors to ensure quality of testing. It also demonstrates the importance of site supervision. We suggest HIV screening laboratories should follow strictly HIV testing procedure and manage normatively. This paper also provides new ideas for the management mode of HIV laboratories in other provinces and even abroad.

\section{Abbreviations}

HIV: Human immunodeficiency virus

AIDS: Acquired immune deficiency syndrome

CDC: Centers for disease control and prevention

SOP: Standard operating procedure

\section{Declarations}

Page 10/15 


\section{Acknowledgments}

We would like to express our gratitude to all the members who participated in site supervision.

\section{Authors' contributions}

All authors participated in data collection. LY and LL conducted data disposal. DY performed the statistical analysis. LL wrote the manuscript. LY was responsible for revising. SL provided professional suggestions. All authors read and approved the final manuscript.

\section{Funding}

This work was supported by Science and Technology Project of Sichuan Provincial Health Committee (20PJ121). The funders had no role in the design of the study and collection, analysis, and interpretation of the data and in the writing of the manuscript.

\section{Availability of data and materials}

All data generated or analyzed during this study were included in this manuscript.

\section{Ethics approval and consent to participate}

Not applicable.

\section{Consent for publication}

Not applicable.

\section{Competing interests}

No conflict of interest to declare.

\section{Footnotes}

Ling Li and Li Ye are co-first authors. Dan Yuan and Shu Liang are co-correspondence authors.

\section{Author details}

Sichuan Center for Disease Control and Prevention, Chengdu, China

\section{References}

1. Ru Lin Fu, Qi Can Peng, Xiao Qin Zhan, Wen Sai Lu, De Rong Wang, Ying Xiong, et al. First AIDS report in Sichuan Province. Journal of LuZhou Medical College,1992,15(04):265-267

2. Li Yan Wang, Qian Qian Qing, Zheng Wei Yu, Chang Cai, Wei Guo, Dong Ming Li, et al. Current Situation of AIDS epidemic in China. Chin J AIDS STD, 2017,v.23;No.163(04):330-333.

3. Bureau of Statistcs in SiChuan Province. SICHUAN WEISHNEG JIANKANG TONGJI NIANJIAN[J].SiChuan: China Statistics, 2011

4. Bureau of Statistcs in SiChuan Province. SICHUAN WEISHNEG JIANKANG TONGJI NIANJIAN[J].SiChuan: China Statistics, 2019

5. http://www.gov.cn/zhengce/content/2017-02/05/content_5165514.htm

6. National AIDS testing management. Chinese Journal of Reproductive Health, 2006,(05):260-264.

7. National Guideline for Detect of HIV/AIDS (2009 revised)[S/OL] 
8. National Guideline for Detect of HIV/AIDS (2015 revised). Chinese Journal of Viral Diseases,2016,v.6(06):401-427.

9. Qiu Chu. Factors AIDS Screening Laboratory Quality Control. China Health Industry,2015,v.12;No.244(17):19-21.

10. Geng Sheng Zhou, Ling Su, Hong Yang, Dan Yuan, Guang Ming Qin, Shu Liang. Quality Control Analysis on Detection Ability of HIV Lymphocyte Immune Phenotype Testing Laboratories in Sichuan Province. Journal of Preventive Medicine Information,2016,v.32(09):925-931.

11. Dan Gao, Xu Wu. The problem should pay attention to AIDS screening laboratory to ensure the quality of testing. Chinese Journal of Health Laboratory Technology,2008,(02):364 + 374 .

12. Xiao Feng Dong, Jia He Sheng, Yi Lv, Yan Wang. Biosafe protection and management in AIDS initial screening test. Henan Medical Research,2010,v.19(02):228-230.

13. National Health commission of the People's Republic of China. [2012]WS/T367-2012.Regulation of disinfection technique in healthcare settings[S]

14. Li Hua Liu, Xian Feng Wang, Hong Zhou, Shu Jun Liu, Jing Dang. Pattern of network construction and management evaluation of HIV screening laboratories in Shijiazhuang City. Practical Preventive Medicine, 2015, v.22(03):311-313.

15. Jiang Y, Qiu M, Zhang G, Xing W, Xiao Y, Pan P, Yao J, Ou CY, Su X. Quality assurance in the HIV/AIDS laboratory network of China. Int J Epidemiol. 2010 Dec;39 Suppl 2(Suppl 2):ii72-8.

16. National Health commission of the People's Republic of China [2015]38.Procedures for the management of HIV infection through occupational exposure. [EB/OL]

17. Dan Yuan, Hong Yang, Ling Su, Li Ye, Hong Lu Liu, Geng Sheng Zhou, Dong Bing Wei, Jia Yu, Guang Ming Qin, Shu Liang. Analysis on the Result of Cross Supervision of AIDS Screening Laboratory in Sichuan Province in 2011-2015. Modern Preventive Medicine, 2016,v.43(22):4208-4211.

\section{Figures}




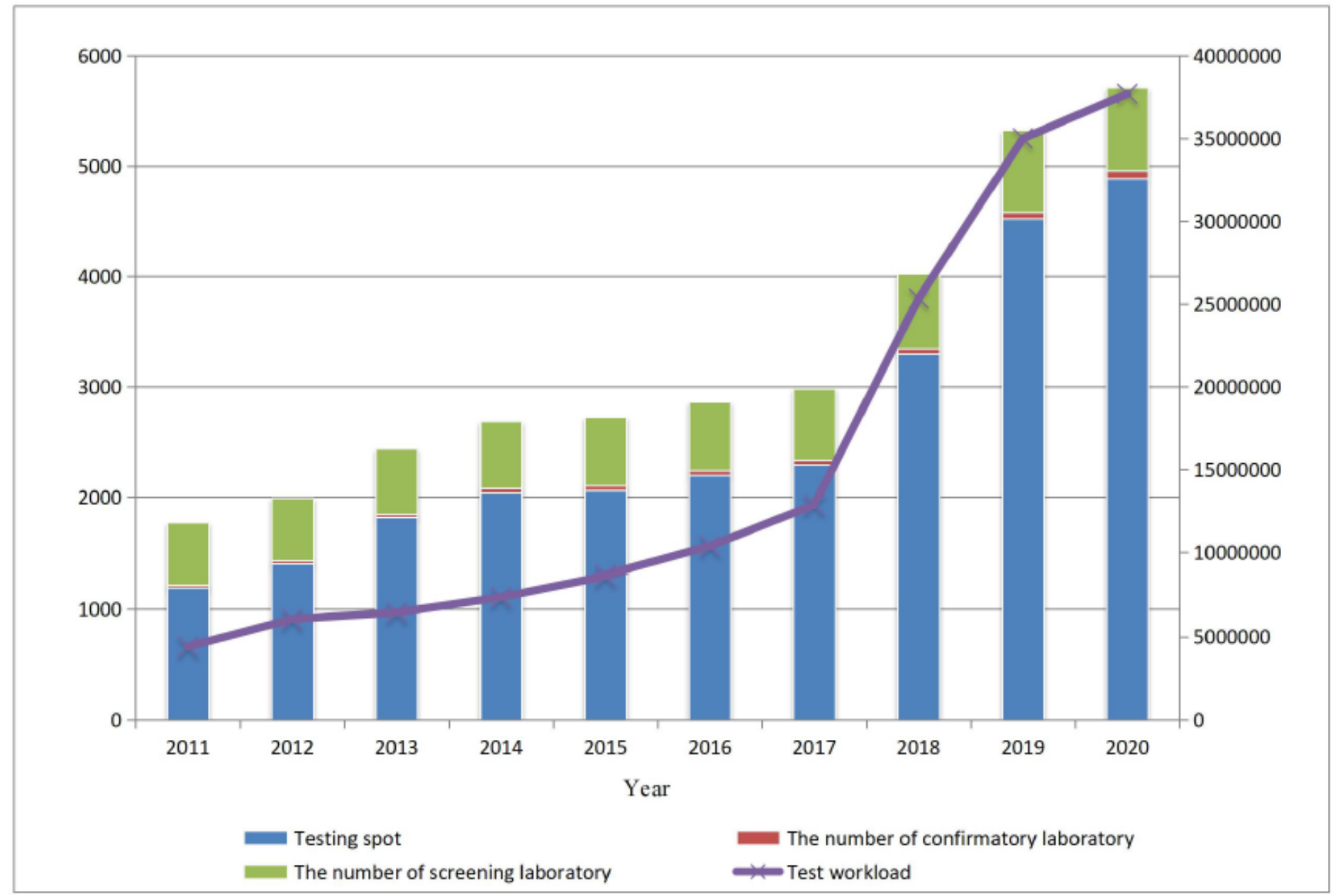

\section{Figure 1}

Changes in the number of HIV testing spot, screening and confirmation laboratories, test workload in Sichuan Province, 20102020 


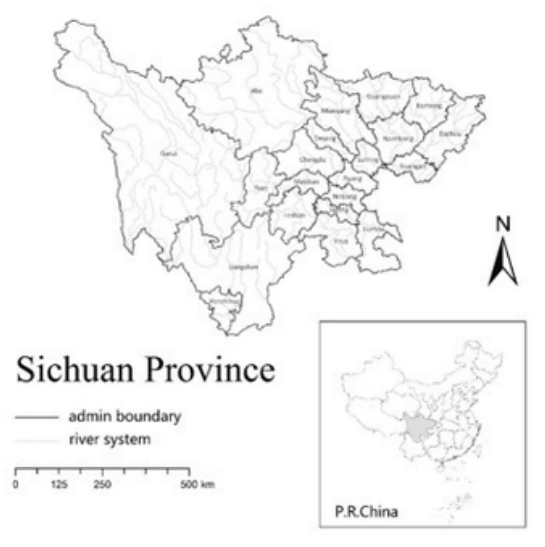

A

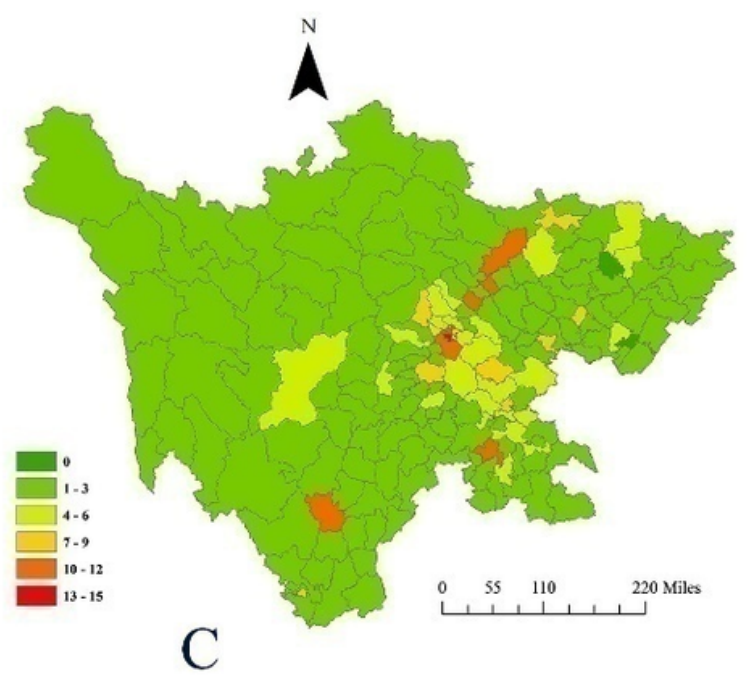

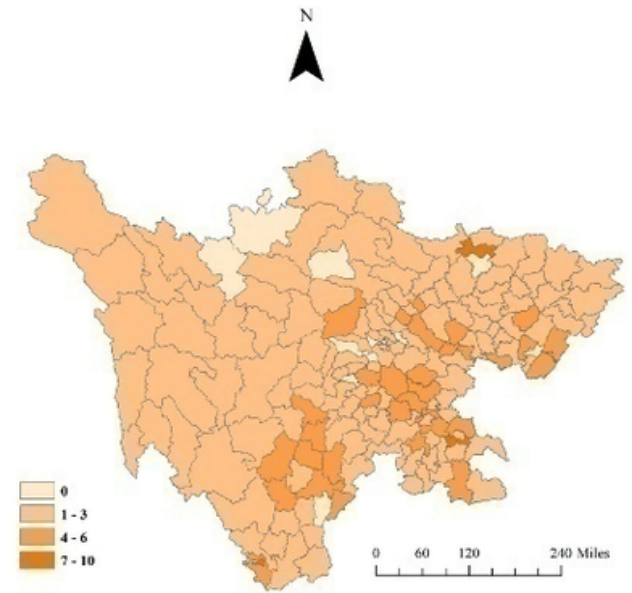

$\mathrm{B}$

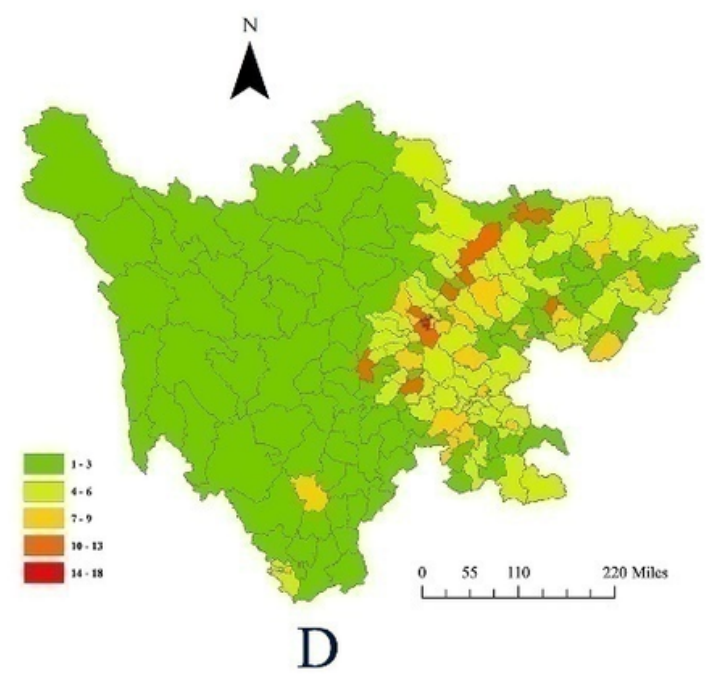

Figure 2

A. An overview map of Sichuan Province B. The distribution Map of frequency of site supervision, 2011-2020 C. The distribution Map of HIV screening laboratory in 2011 D. The distribution Map of HIV screening laboratory in 2020 Note: The map in this figure is designed by using the ArcMap 10.6 software. 


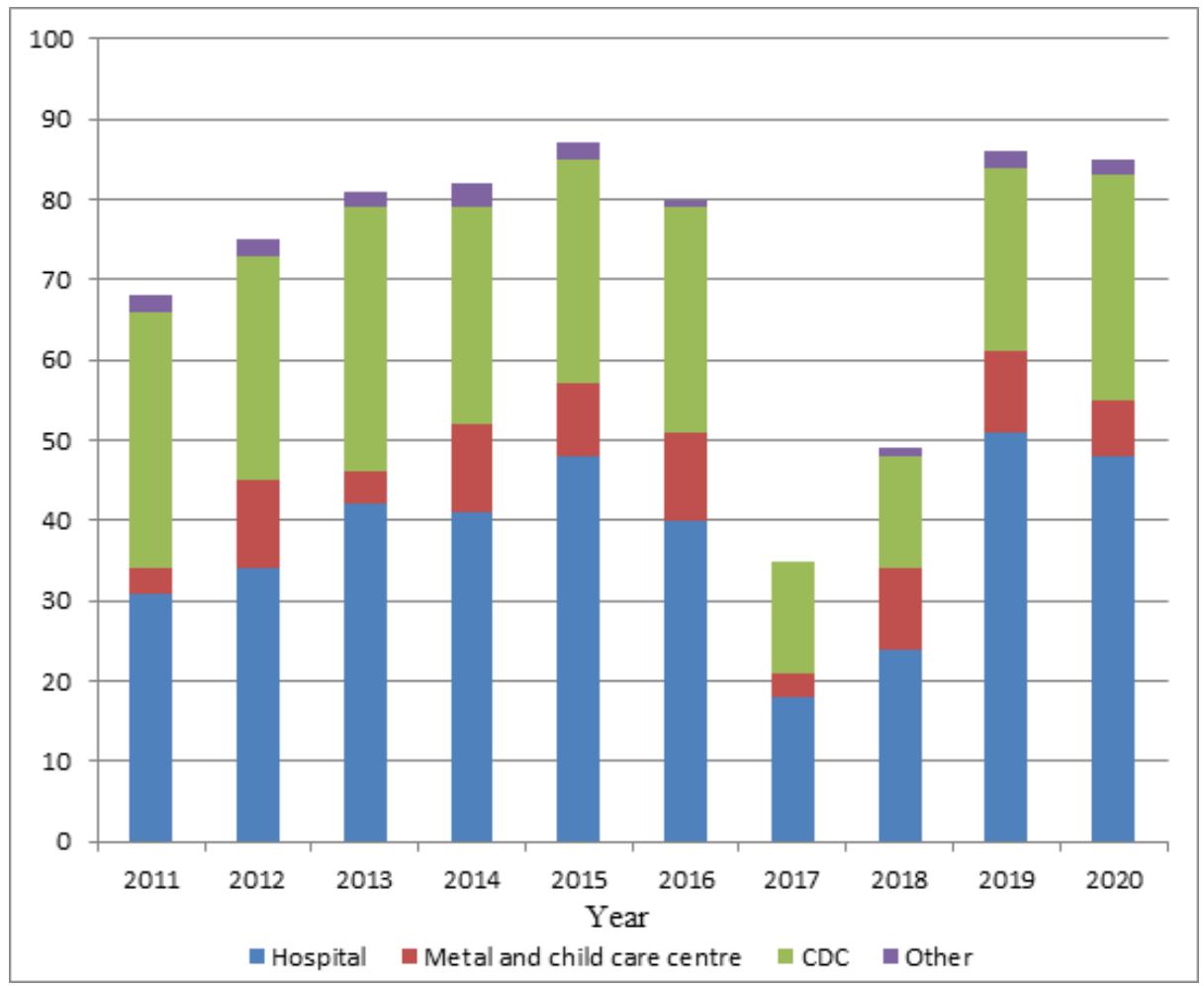

\section{Figure 3}

The number of site supervised laboratories and distribution of institution types, 2010-2020 Note: 2017 and 2018 were two years to complete a round of site supervision, so the numbers differed significantly from other years 